\title{
Elective induction versus spontaneous labor at term: prospective study of outcome and complications
}

\author{
Sagarika Babu*, Lakshmi Manjeera M.
}

Department of Obstetrics and Gynecology, K. S. Hegde Medical Academy, Mangalore, Karnataka, India

Received: 13 August 2017

Revised: 02 October 2017

Accepted: 06 October 2017

\section{*Correspondence: \\ Dr. Sagarika Babu, \\ E-mail: sgrkbb@gmail.com}

Copyright: (c) the author(s), publisher and licensee Medip Academy. This is an open-access article distributed under the terms of the Creative Commons Attribution Non-Commercial License, which permits unrestricted non-commercial use, distribution, and reproduction in any medium, provided the original work is properly cited.

\section{ABSTRACT}

Background: This study aims at identifying the association between inductions of labor in nullipara and multipara to caesarean delivery and other associated maternal and neonatal outcomes.

Methods: The study subjects were divided into two groups, elective induction group and spontaneous labor group. They were matched for maternal age, parity and gestational age. Duration of first and second stage of labor, mode of delivery, if caesarean section, indication for caesarean section and its relation to Bishop score, maternal age, birth weight was analyzed. Maternal intrapartum and post-partum complications and fetal outcome were also analyzed.

Results: Out of the 400 women in the study, 200 were induced and 200 were those who went into spontaneous labor. The rate of cesarean section rate among induced group is $31 \%$ and was statistically significant. But the analysis of the same after excluding risk factors like nulliparity, Bishop score $<5$ and birth weight $>3.5 \mathrm{~kg}$ it was found that the rate of cesarean section is $37.1 \%$, but was statistically not significant when compared to the spontaneous group.There was significant decrease in the duration of second stage of labor in the induced primipara group with $\mathrm{p}$ value of 0.038 . There was no significant difference in the maternal and neonatal complications.

Conclusions: This study concludes that elective induction in carefully selected low risk population, excluding the above-mentioned risk factors does not pose any increased risk of cesarean section. Elective induction does not cause any increased risk to mother and fetus.

Keywords: Foetal outcome caesarean delivery, Induction of labour, Maternal outcome

\section{INTRODUCTION}

Obstetrics is the health science that deals with pregnancy and child birth and post-partum period. It deals with two lives, the mother and the fetus. Most of the women during their reproductive years are healthy and have an uncomplicated delivery of a healthy baby at term with spontaneous onset of labor. When the situation arises to interrupt the pregnancy in interest of the mother or fetus or both, where the continuation of pregnancy will pose an adverse outcome for mother and child induction of labor is one of the means. It is among the most common obstetric interventions being done now. WHO Global
Survey on Maternal and Perinatal Health, which included 373 healthcare facilities in 24 countries and nearly 300 000 deliveries, showed that $9.6 \%$ of the deliveries involved labor induction. ${ }^{1}$ According to the National Center for Health Statistics, the incidence of labor induction in the United States more than doubled from $9.5 \%$ in 1991 to $22.5 \%$ in $2006 .^{2}$

Rate of induction in India being reported as $11.4 \%$ (Misra and Vavre, 1994). Rate of elective induction of labor is at rapid rise, more rapidly than the overall induction of labor. For example, Zhang et al. reported that the overall labor induction rate increased from 9.5 percent to 19.4 
percent from 1990 to 1998 , and the increase for clinically indicated induction was less. ${ }^{3}$

Elective induction of labor means initiation of labor at term pregnancy without any acceptable medical or obstetric indication. ${ }^{4}$ It may be motivated by a variety of reasons and has been utilized since decades. For example, pregnant woman may wish to end their pregnancy because of physical discomfort, to avoid potential adverse outcomes associated with post-term pregnancy like increased risk of perinatal mortality, meconium aspiration and intrauterine infection for neonate as well as increased risk of perineal trauma, labor dystocia and caesarean delivery for the mother. It allows delivery during the daytime so that better perinatal medical care, better planning by physician and pregnant woman and their families are possible. But inducing labor may also pose risks such as uterine hyper stimulation, infection, rupture uterus, cord prolapse, iatrogenic prematurity and failed induction resolved by cesarean delivery. Hence it is imperative to determine the potential outcomes associated with elective induction of labor. There are few prospective, randomized controlled trials where the rates of cesarean delivery were low or unchanged among induced and spontaneous labor group, whereas few trials showed an increase in the rate of cesarean delivery. Hence there is a critical uncertainty about the effect of elective induction of labor on the rate of cesarean delivery. Thus, determining the effect of elective induction of labor on caesarean delivery as well as other maternal and neonatal outcomes is important.

This study aims at identifying the association between induction of labor in nullipara and multipara to caesarean delivery and other associated maternal and neonatal outcomes. And to observe whether electively induced labor will pose the mother and fetus at an increased risk as compared with her spontaneous labor cohort.

The main objective of this study is to determine the influence of induction of labor on caesarean delivery. Other objectives being, to determine and compare the maternal outcomes like meconium stained liquor amnii, any prolongation in duration of labor, uterine hyperstimulation, mode of delivery whether instrumental delivery or caesarean delivery and delivery complications like atonic post-partum hemorrhage, traumatic postpartum hemorrhage, retained placenta, cord prolapse, still birth, in induced labor group with their counterparts. This study also compares neonatal outcomes like intrapartum cardiotocography abnormalities, birth injuries in instrumental deliveries, perinatal mortality and NICU admissions for meconium aspiration, hyperbilirubinemia, respiratory distress in induced labor group with their counterparts.

\section{METHODS}

This is a prospective clinical study conducted at Justice K. S. Hegde Charitable Hospital, Deralakatte, Mangalore,
Karnataka, India. It is a cross sectional observational study. The study population consists of 200 subjects in the elective induction group and 200 subjects in spontaneous labor group. It was conducted from October 2014 to September 2016.

The inclusion criteria of the study subjects were a singleton live fetus, gestational age of 370/7 weeks and above up to $416 / 7$ weeks, clinically suspected decreased amniotic fluid but AFI $>5$, subjects complaining of decreased fetal movements but NST is reactive, no medical contraindication for induction of labor, prelabor rupture of membrane and willingness to participate in the study. Exclusion criteria being non-cephalic presentation, intrauterine growth restriction, oligohydramnios, polyhydramnios, pre-eclampsia, gestational diabetes mellitus, fetal congenital anomaly, hydrocephalus or cystic hygroma, placenta praevia, abruptio placenta, contracted pelvis or cephalo pelvic disproportion, previous LSCS.

A written informed consent was obtained from each subject participating in the study.

For the purpose of the study subjects were divided into two groups, elective induction group and spontaneous labor group. They were matched for maternal age, parity and gestational age. Analysis was performed in two ways: cesarean delivery after induction will be compared with after spontaneous labor, induction at a given gestational age will be compared with expectant management of all other women at or after that gestational age (at-or-above comparison group). Those who matched with the inclusion criteria were induced with either oxytocin, prostaglandins or by artificial rupture of membranes or combination of these and they constitute the electively induced group. Spontaneous labor is labor in the absence of pharmacologic or mechanical initiation. Duration of first and second stage of labor, mode of delivery, if caesarean section, indication for caesarean section and its relation to Bishop score, maternal age, birth weight was analyzed. Maternal intrapartum and post-partum complications and fetal outcome were also analyzed in both the groups.

\section{Statistical analysis}

The obtained data was analyzed, coded and entered. The data was statistically analyzed using SPSS software using tests like Chi-square test and unpaired t test.

\section{RESULTS}

In this study, a total of 400 patients were enrolled, which included 200 patients in the induction group (study group) and 200 patients in the spontaneous labor group (control group).

Women in the spontaneous group had a mean age of 26.54 years and in the induced group had a mean age of 
26.48 years. This was statistically non-significant with a $\mathrm{p}$ value of 0.887 and hence was comparable. Comparison of the period of gestation (POG) in days between the two groups shows that POG (days) is higher in induced group with a mean value of 280.82 and spontaneous group mean POG 274.42. This is statistically significant with a $\mathrm{p}$ value of $<0.001$.

Table 1: Age and POG distribution.

\begin{tabular}{|llllll|}
\hline \multirow{2}{*}{ Age } & Group & N & Mean & Std. deviation & P value \\
& Induced & 200 & 26.48 & 3.923 & 0.887 \\
\cline { 2 - 5 } POG (days) & Spontaneous & 200 & 26.54 & 3.78 & $<0.001$ \\
& Induced & 200 & $280.82(40 w k+1 d)$ & 4.314 & 7.955 \\
& Spontaneous & 200 & $274.42(39 w k+2 d)$ & & \\
\hline
\end{tabular}

There was significant difference between the parity distributions in both the groups, with a $\mathrm{p}$ value of 0.015 . Most women in the induced group were primipara comprising $63.5 \%$ and multigravida comprising $36.5 \%$. Primipara in the spontaneous group comprised $51.5 \%$ and multigravida $48.5 \%$.

Table 2: Parity distribution.

\begin{tabular}{|c|c|c|c|c|c|}
\hline \multicolumn{6}{|c|}{ Parity } \\
\hline & & & Group & & \\
\hline & & & Induced & Spontaneous & Total \\
\hline \multirow{4}{*}{ Parity } & \multirow{2}{*}{ Primipara } & Count & 127 & 103 & 230 \\
\hline & & $\%$ within group & $63.5 \%$ & $51.5 \%$ & $57.5 \%$ \\
\hline & \multirow{2}{*}{ Multipara } & Count & 73 & 97 & 170 \\
\hline & & $\%$ within group & $36.5 \%$ & $48.5 \%$ & $42.5 \%$ \\
\hline \multicolumn{2}{|l|}{ Total } & Count & 200 & 200 & 400 \\
\hline
\end{tabular}

Out of 200 women induced, 166 were induced with prostaglandins and 34 were induced with ARM and oxytocin.

In the present study the comparison of duration of first stage of labor among the primipara between the induced and spontaneous group shows higher duration in spontaneous group. This was statistically non-significant with a $\mathrm{p}$ value of 0.639 . Comparison of the duration of second stage (mins) between the two groups shows that duration of second stage (mins) is higher in spontaneous group and is statistically significant with a $\mathrm{p}$ value of 0.038. Similarly, among the multipara the comparison of duration of first stage of labor between the induced and spontaneous group showed higher duration in spontaneous group. This was statistically non-significant with a $\mathrm{p}$ value of 0.338 .

Table 3: Duration of first and second stage of labor.

\begin{tabular}{|c|c|c|c|c|c|}
\hline & & Group & Mean & Std. Deviation & P value \\
\hline \multirow[t]{4}{*}{ Primipara } & \multirow{2}{*}{ Duration of first stage (hrs) } & Induced & 6.65 & 2.944 & \multirow{2}{*}{0.639} \\
\hline & & Spontaneous & 6.85 & 2.606 & \\
\hline & \multirow{2}{*}{ Duration of second stage (mins) } & Induced & 21.90 & 14.93 & \multirow{2}{*}{0.038} \\
\hline & & Spontaneous & 27.27 & 17.19 & \\
\hline \multirow[t]{4}{*}{ Multipara } & \multirow{2}{*}{ Duration of first stage (hrs) } & Induced & 4.73 & 1.638 & \multirow{2}{*}{0.338} \\
\hline & & Spontaneous & 5.07 & 2.841 & \\
\hline & \multirow{2}{*}{ Duration of second stage (mins) } & Induced & 19.22 & 11.10 & \multirow{2}{*}{0.058} \\
\hline & & Spontaneous & 15.99 & 9.74 & \\
\hline
\end{tabular}


Comparison of the duration of second stage(mins) between the two groups shows that duration of second stage (mins) is higher in induced group and is statistically non significant with a $\mathrm{p}$ value of 0.058 .

Table 4: Comparison of the mode of delivery between the group.

\begin{tabular}{|c|c|c|c|c|c|}
\hline \multicolumn{6}{|c|}{ Mode of delivery } \\
\hline & & & Group & & Total \\
\hline & & & Induced & Spontaneous & \\
\hline \multirow{6}{*}{$\begin{array}{l}\text { Mode of } \\
\text { delivery }\end{array}$} & \multirow{2}{*}{ Vaginal } & Count & 130 & 165 & 295 \\
\hline & & $\%$ within group & $65.0 \%$ & $82.5 \%$ & $73.8 \%$ \\
\hline & \multirow{2}{*}{ Instrumental } & Count & 8 & 11 & 19 \\
\hline & & $\%$ within group & $4.0 \%$ & $5.5 \%$ & $4.8 \%$ \\
\hline & \multirow{2}{*}{ Cesarean section } & Count & 62 & 24 & 86 \\
\hline & & $\%$ within group & $31.0 \%$ & $12.0 \%$ & $21.5 \%$ \\
\hline \multicolumn{2}{|l|}{ Total } & Count & 200 & 200 & 400 \\
\hline
\end{tabular}

Table 5: Percentage distribution by mode of delivery for subgroups defined by parity.

\begin{tabular}{|c|c|c|c|c|c|}
\hline \multicolumn{6}{|c|}{ Mode of delivery } \\
\hline & & & Induced & Spontaneous & Total \\
\hline \multicolumn{6}{|l|}{ Primipara } \\
\hline \multirow{6}{*}{$\begin{array}{l}\text { Mode of } \\
\text { delivery }\end{array}$} & \multirow{2}{*}{ Vaginal } & Count & 69 & 73 & 142 \\
\hline & & $\%$ within group & $54.3 \%$ & $70.9 \%$ & $61.7 \%$ \\
\hline & \multirow{2}{*}{ Instrumental } & Count & 7 & 10 & 17 \\
\hline & & $\%$ within group & $5.5 \%$ & $9.7 \%$ & $7.4 \%$ \\
\hline & \multirow{2}{*}{ Cesarean section } & Count & 51 & 20 & 71 \\
\hline & & $\%$ within group & $40.2 \%$ & $19.4 \%$ & $30.9 \%$ \\
\hline Total & & Count & 127 & 103 & 230 \\
\hline \multicolumn{6}{|l|}{ Multi } \\
\hline \multirow{6}{*}{$\begin{array}{l}\text { Mode of } \\
\text { delivery }\end{array}$} & \multirow{2}{*}{ Vaginal } & Count & 61 & 92 & 153 \\
\hline & & $\%$ within group & $83.6 \%$ & $94.8 \%$ & $90.0 \%$ \\
\hline & \multirow{2}{*}{ Instrumental } & Count & 1 & 1 & 2 \\
\hline & & $\%$ within group & $1.4 \%$ & $1.0 \%$ & $1.2 \%$ \\
\hline & \multirow{2}{*}{$\begin{array}{l}\text { Cesarean } \\
\text { section }\end{array}$} & Count & 11 & 4 & 15 \\
\hline & & $\%$ within group & $15.1 \%$ & $4.1 \%$ & $8.8 \%$ \\
\hline Total & & Count & 73 & 97 & 170 \\
\hline
\end{tabular}

In the present study, the induction group is associated with increase in cesarean section rates of upto $31 \%$ when compared to that of spontaneous group which is $12 \%$. This is statistically significant with a $\mathrm{p}$ value of $<0.001$. The rate of cesarean section in the primiparous induced women is $51 \%$ and $20 \%$ in the primiparous spontaneous group.

The rate of vaginal delivery is more in the primiparous spontaneous group which is $70.9 \%$ and $54.3 \%$ in induced group. This is statistically significant with a $\mathrm{p}$ value of 0.003 . The cesarean section rates in the multiparous induced group are $11 \%$ and in multiparous spontaneous group is $4 \%$. In multiparous, the rate of vaginal delivery is $83.6 \%$ and $94.8 \%$ in induced and spontaneous group respectively. This is statistically significant with a $\mathrm{p}$ value of 0.043 .

Among the induced group, patients with Bishop score $<5$ had a cesarean rate of $45.3 \%$, when compared to $14.3 \%$ in those with Bishop score $\geq 5$ among the primiparous. This was statistically significant, with a $\mathrm{p}$ value of 0.011 . This significance was seen only in primiparous group and not in multiparous group.

In this present study, most of the babies who delivered where among $3.1-3.5 \mathrm{~kg}$. Only 36 out of 400 babies were $>3.5 \mathrm{~kg}$. The risk of cesarean among the fetus with $>3.5 \mathrm{~kg}$ birth weight is $41.7 \%$. This is statistically significant with a $\mathrm{p}$ value of 0.033 . 
Table 6: Mode of delivery by parity and bishop score in the induced group.

\begin{tabular}{|c|c|c|c|c|c|}
\hline \multicolumn{6}{|c|}{ Mode of delivery } \\
\hline \multirow{2}{*}{ Parity } & & & \multicolumn{2}{|c|}{ Bishop score } & \multirow{2}{*}{ Total } \\
\hline & & & $<5$ & $\geq \mathbf{5}$ & \\
\hline \multicolumn{6}{|l|}{ Primipara } \\
\hline \multirow{6}{*}{$\begin{array}{l}\text { Mode of } \\
\text { delivery }\end{array}$} & \multirow{2}{*}{ Vaginal } & Count & 54 & 15 & 69 \\
\hline & & $\%$ within bishop score & $50.9 \%$ & $71.4 \%$ & $54.3 \%$ \\
\hline & \multirow{2}{*}{ Instrumental } & Count & 4 & 3 & 7 \\
\hline & & $\%$ within bishop score & $3.8 \%$ & $14.3 \%$ & $5.5 \%$ \\
\hline & \multirow{2}{*}{ Cesarean section } & Count & 48 & 3 & 51 \\
\hline & & $\%$ within bishop score & $45.3 \%$ & $14.3 \%$ & $40.2 \%$ \\
\hline Total & & Count & 106 & 21 & 127 \\
\hline \multicolumn{6}{|l|}{ Multipar } \\
\hline \multirow{6}{*}{$\begin{array}{l}\text { Mode of } \\
\text { delivery }\end{array}$} & \multirow{2}{*}{ Vaginal } & Count & 51 & 10 & 61 \\
\hline & & $\%$ within bishop score & $82.3 \%$ & $90.9 \%$ & $83.6 \%$ \\
\hline & \multirow{2}{*}{ Instrumental } & Count & 1 & 0 & 1 \\
\hline & & $\%$ within bishop score & $1.6 \%$ & $0.0 \%$ & $1.4 \%$ \\
\hline & \multirow{2}{*}{ Cesarean section } & Count & 10 & 1 & 11 \\
\hline & & $\%$ within bishop score & $16.1 \%$ & $9.1 \%$ & $15.1 \%$ \\
\hline \multicolumn{2}{|l|}{ Total } & Count & 62 & 11 & 73 \\
\hline
\end{tabular}

Table 7: Birth weight of the fetus and its relation to mode of delivery.

\section{Mode of delivery}

\section{Mode of delivery}

Vaginal

Instrumental

Cesarean section

Total

\begin{tabular}{l} 
Count \\
\hline$\%$ within group \\
Count \\
\hline$\%$ within group \\
Count \\
\hline$\%$ within group \\
Count \\
\hline
\end{tabular}

Birth weight $(\mathrm{Kg})$

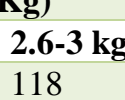

$80.3 \%$

8

$5.4 \%$

21

$14.3 \%$

147

\begin{tabular}{lll}
$\mathbf{3 1 . - 3 . 5} \mathbf{~ k g}$ & $\mathbf{> 3 . 5} \mathbf{~ k g}$ & Total \\
\cline { 1 - 2 } 131 & 20 & 295 \\
\hline $72.4 \%$ & $55.6 \%$ & $73.8 \%$ \\
\hline 8 & 1 & 19 \\
$4.4 \%$ & $2.8 \%$ & $4.8 \%$ \\
\hline 42 & 15 & 86 \\
$23.2 \%$ & $41.7 \%$ & $21.5 \%$ \\
181 & 36 & 400
\end{tabular}

Table 8: Analysis to assess the risk of cesarean section in induced and spontaneous group.

\begin{tabular}{|c|c|c|c|c|}
\hline \multirow{2}{*}{\multicolumn{2}{|c|}{ Mode of delivery ${ }^{\text {a }}$}} & \multicolumn{2}{|c|}{ Bishop Score } & \multirow{2}{*}{ Total } \\
\hline & & $<5$ & $\geq 5$ & \\
\hline \multirow[b]{2}{*}{ Vaginal } & Count & 52 & 13 & 65 \\
\hline & $\begin{array}{l}\% \text { within } \\
\text { BISHOP } \\
\text { Score }\end{array}$ & $58.4 \%$ & $68.4 \%$ & $60.2 \%$ \\
\hline \multirow[b]{2}{*}{ Instrumental } & Count & 4 & 3 & 7 \\
\hline & $\begin{array}{l}\% \text { within } \\
\text { BISHOP } \\
\text { Score }\end{array}$ & $4.5 \%$ & $15.8 \%$ & $6.5 \%$ \\
\hline \multirow[b]{2}{*}{$\begin{array}{l}\text { Cesarean } \\
\text { section }\end{array}$} & Count & 33 & 3 & 36 \\
\hline & $\begin{array}{l}\% \text { within } \\
\text { BISHOP } \\
\text { Score }\end{array}$ & $37.1 \%$ & $15.8 \%$ & $33.3 \%$ \\
\hline Total & Count & 89 & 19 & 108 \\
\hline
\end{tabular}

${ }^{\text {a }}$ Parity $=$ primi, age $=<30$, birth weight $=<3.5$

Further the 2 groups i.e. the induced and spontaneous groups were analyzed after excluding the risk factors to assess whether induction per se is associated with increased cesarean section rates.

The cesarean section rates among the induced nulliparous women compared to her spontaneous labor group after excluding the risk factors were comparable. Hence there is no statistically significant increase on cesarean section rates among the induced group when the risk factors are nullified

In this study the most common indication for cesarean section among the induced group is failed induction followed by fetal distress and then meconium stained liquor. Among the spontaneous group the most common indication is fetal distress.

In the present study the most common complication among the induced group is atonic PPH $(n=4)$. Among the spontaneous group the most common complications were atonic PPH $n=2$, perineal tear $n=2$ and vaginal tear $n=2$. There is no statistically significant increased risk of maternal complications between the two groups, 
with $\mathrm{p}$ value 0.287 . The rate of maternal complication is $3.5 \%$ in induced group where as it is $5 \%$ in the spontaneous group.

Table 9: Indication for cesarean section.

\begin{tabular}{|c|c|c|c|}
\hline \multirow{2}{*}{\multicolumn{2}{|c|}{$\begin{array}{l}\text { Indication for cesarean } \\
\text { section }\end{array}$}} & \multicolumn{2}{|l|}{ Group } \\
\hline & & Induced & Spontaneous \\
\hline \multirow{2}{*}{$\begin{array}{l}\text { Arrest of } \\
\text { descent }\end{array}$} & Count & 4 & 5 \\
\hline & $\begin{array}{l}\text { \% Within } \\
\text { group }\end{array}$ & $6.5 \%$ & $20.8 \%$ \\
\hline \multirow{2}{*}{$\begin{array}{l}\text { Failed } \\
\text { induction }\end{array}$} & Count & 37 & 0 \\
\hline & $\begin{array}{l}\text { \% Within } \\
\text { group }\end{array}$ & $59.7 \%$ & $0.0 \%$ \\
\hline \multirow{2}{*}{ Fetal distress } & Count & 11 & 14 \\
\hline & $\begin{array}{l}\% \text { Within } \\
\text { group }\end{array}$ & $17.7 \%$ & $58.3 \%$ \\
\hline \multirow{2}{*}{$\begin{array}{l}\text { Meconium } \\
\text { stained } \\
\text { liquor }\end{array}$} & Count & 3 & 4 \\
\hline & $\begin{array}{l}\% \text { Within } \\
\text { group }\end{array}$ & $4.8 \%$ & $16.7 \%$ \\
\hline \multirow{2}{*}{$\begin{array}{l}\text { Secondary } \\
\text { arrest of } \\
\text { dilatation }\end{array}$} & Count & 7 & 1 \\
\hline & $\begin{array}{l}\% \text { Within } \\
\text { group }\end{array}$ & $11.3 \%$ & $4.2 \%$ \\
\hline Total & Count & 62 & 24 \\
\hline
\end{tabular}

Chi-square value is 31.467 and $p$ value is $<0.001$

Table 10: Maternal complications.

\begin{tabular}{|c|c|c|c|}
\hline \multirow{2}{*}{\multicolumn{2}{|c|}{ Maternal complications }} & \multicolumn{2}{|l|}{ Group } \\
\hline & & \multirow{2}{*}{$\begin{array}{l}\text { Induced } \\
193\end{array}$} & \multirow{2}{*}{$\begin{array}{l}\text { Spontaneous } \\
190\end{array}$} \\
\hline \multirow{2}{*}{ Nil } & Count & & \\
\hline & $\begin{array}{l}\% \text { within } \\
\text { group }\end{array}$ & $96.5 \%$ & $95.0 \%$ \\
\hline \multirow{2}{*}{ Atonic pph } & Count & 4 & 2 \\
\hline & $\begin{array}{l}\% \text { within } \\
\text { group }\end{array}$ & $2.0 \%$ & $1.0 \%$ \\
\hline \multirow{2}{*}{$\begin{array}{l}\text { Cervical } \\
\text { tear }\end{array}$} & Count & 1 & 1 \\
\hline & $\begin{array}{l}\% \text { within } \\
\text { group }\end{array}$ & $0.5 \%$ & $0.5 \%$ \\
\hline \multirow{2}{*}{$\begin{array}{l}\text { Episiotomy } \\
\text { wound } \\
\text { infection }\end{array}$} & Count & 0 & 1 \\
\hline & $\begin{array}{l}\% \text { within } \\
\text { group }\end{array}$ & $0.0 \%$ & $0.5 \%$ \\
\hline \multirow{2}{*}{$\begin{array}{l}\text { Meconium } \\
\text { stained } \\
\text { liquor }\end{array}$} & Count & 0 & 1 \\
\hline & $\begin{array}{l}\% \text { within } \\
\text { group }\end{array}$ & $0.0 \%$ & $0.5 \%$ \\
\hline \multirow{2}{*}{$\begin{array}{l}\text { Perineal } \\
\text { tear }\end{array}$} & Count & 0 & 2 \\
\hline & $\begin{array}{l}\% \text { within } \\
\text { group }\end{array}$ & $0.0 \%$ & $1.0 \%$ \\
\hline \multirow{2}{*}{$\begin{array}{l}\text { Poor } \\
\text { maternal } \\
\text { bearing } \\
\text { down }\end{array}$} & Count & 2 & 0 \\
\hline & $\begin{array}{l}\text { \% within } \\
\text { group }\end{array}$ & $1.0 \%$ & $0.0 \%$ \\
\hline \multirow{2}{*}{$\begin{array}{l}\text { Puerperal } \\
\text { sepsis }\end{array}$} & Count & 0 & 1 \\
\hline & $\begin{array}{l}\% \text { within } \\
\text { group }\end{array}$ & $0.0 \%$ & $0.5 \%$ \\
\hline \multirow[b]{2}{*}{$\begin{array}{l}\text { Vaginal } \\
\text { tear }\end{array}$} & Count & 0 & 2 \\
\hline & $\begin{array}{l}\% \text { within } \\
\text { group }\end{array}$ & $0.0 \%$ & $1.0 \%$ \\
\hline Total & Count & 200 & 200 \\
\hline
\end{tabular}

Chi-square test value is 9.690 and $p$ value is 0.287
In this study, the most common fetal complications among the induced group is hyperbilirubinemia $n=17$ and followed by intrapartum fetal variable decelerations. Among the spontaneous group also the common complications remain the same with hyperbilirubinemia $\mathrm{n}$ $=7$ and followed by variable decelerations $n=4$. Fetal complications among the induced group and spontaneous group are comparable, with a $\mathrm{p}$ value of 0.368 . The rate of fetal complications in the induced group is $14 \%$ and in spontaneous group is $8.5 \%$ in this present study.

Table 11: Fetal complications.

\begin{tabular}{|c|c|c|c|}
\hline \multirow{2}{*}{\multicolumn{2}{|c|}{$\begin{array}{l}\text { Fetal } \\
\text { complications }\end{array}$}} & \multicolumn{2}{|l|}{ Group } \\
\hline & & \multirow{2}{*}{$\begin{array}{l}\text { Induced } \\
172\end{array}$} & \multirow{2}{*}{$\begin{array}{l}\text { Spontaneous } \\
183\end{array}$} \\
\hline & Count & & \\
\hline Nil & $\begin{array}{l}\% \text { within } \\
\text { group }\end{array}$ & $86.0 \%$ & $91.5 \%$ \\
\hline \multirow[b]{2}{*}{ Bradycardia } & Count & 1 & 0 \\
\hline & $\begin{array}{l}\text { \% within } \\
\text { group }\end{array}$ & $0.5 \%$ & $0.0 \%$ \\
\hline \multirow[b]{2}{*}{$\begin{array}{l}\text { Early } \\
\text { deceleration }\end{array}$} & Count & 0 & 1 \\
\hline & $\begin{array}{l}\text { \% within } \\
\text { group }\end{array}$ & $0.0 \%$ & $0.5 \%$ \\
\hline \multirow[b]{2}{*}{$\begin{array}{l}\text { Hyper- } \\
\text { bilirubinemia }\end{array}$} & Count & 17 & 7 \\
\hline & $\begin{array}{l}\% \text { within } \\
\text { group }\end{array}$ & $8.5 \%$ & $3.5 \%$ \\
\hline \multirow{2}{*}{$\begin{array}{l}\text { Late } \\
\text { deceleration }\end{array}$} & Count & 1 & 0 \\
\hline & $\begin{array}{l}\% \text { within } \\
\text { group }\end{array}$ & $0.5 \%$ & $0.0 \%$ \\
\hline \multirow{2}{*}{$\begin{array}{l}\text { Meconium } \\
\text { aspiration }\end{array}$} & Count & 0 & 1 \\
\hline & $\begin{array}{l}\% \text { within } \\
\text { group }\end{array}$ & $0.0 \%$ & $0.5 \%$ \\
\hline \multirow[b]{2}{*}{$\begin{array}{l}\text { Respiratory } \\
\text { distress }\end{array}$} & Count & 3 & 2 \\
\hline & $\begin{array}{l}\% \text { within } \\
\text { group }\end{array}$ & $1.5 \%$ & $1.0 \%$ \\
\hline \multirow[b]{2}{*}{ Tachycardia } & Count & 2 & 2 \\
\hline & $\begin{array}{l}\% \text { within } \\
\text { group }\end{array}$ & $1.0 \%$ & $1.0 \%$ \\
\hline \multirow{2}{*}{$\begin{array}{l}\text { Variable } \\
\text { deceleration }\end{array}$} & Count & 4 & 4 \\
\hline & $\begin{array}{l}\% \text { within } \\
\text { group }\end{array}$ & $2.0 \%$ & $2.0 \%$ \\
\hline
\end{tabular}

Chi-square test value is 8.708 and $p$ value is 0.368

The need for NICU admission was 7 in induced group and 13 in spontaneous group in this study. This is however statistically not significant with a $p$ value of 0.169 .

\section{DISCUSSION}

Labor induction rate nationwide has gradually increased. It is evident from the fact that rate of elective induction is on the rise as the increase in medically indicated induction is less than the overall increase. Elective induction is done so that delivery happens as per physician's convenience. It is also done due to patients desire to end their pregnancy because of physical discomfort. Thus, it is imperative to determine the 
potential effects and outcomes associated with elective induction of labor.

Although only limited literature is available on elective induction, its advantages and disadvantages have been described. This prospective study on the effect of elective induction of labor on the mother and fetus have been conducted with the aim not to validate or promote elective induction but to rather identify whether electively induced labor actually places the mother and her fetus at increased risk as compared with her spontaneous labor group in low risk patients and also to determine the influence of labor induction on cesarean delivery.

In this study, both the induced and spontaneous group population is comparable by maternal age. There was difference in the mean gestational age which is probably because the spontaneous group population going into labor before the expected date of delivery and the induced group, most of them being induced after crossing of their expected date of delivery. There was difference in the parity, with induced group comprising of more primigravida compared to multigravida.

The multigravida went into spontaneous labor earlier than the primigravida. The indications for elective induction in e study group were as follows, 175 women were induced in view of crossed EDD, 22 cases were those who came with prelabor rupture of membranes and did not go into labor after 6 hours and were willing for labor induction and 3 cases for clinically less liqoramnii but AFI $>5$ by ultrasound.

In this present study, the risk of cesarean section in the nulliparous induced group is $40.2 \%$ and the multiparous group is $15.1 \%$. On comparing all the other similar studies the risk of cesarean section rates in the nulliparous women is more than the multiparous group, which is similar to our study. Moreover, the risk of ceasarean section is more in induced group that $31 \%$ and is less in spontaneous group that is $15 \%$, which is also comparable with other studies. Similar to the present study the studies done by Macer et al, Maslow and Sweeny et al, Prysak et al also found an increased risk of cesarean rate in nulliparous induced women..$^{5-7}$

Comparison of the rate of cesarean section in relation to the Bishop score prior to induction, clearly reveals that the cesarean section rate is more when the Bishop score $<5$ and hence the cervical status plays an important role in elective induction of labor and its outcome. In the present study, Bishop score $<5$ is associated with $45.3 \%$ risk of cesarean section where as the rate is $14.3 \%$ when the Bishop score $\geq 5$ among the nulliparous induced group. Even in the multiparous group the rate of cesarean section is more when Bishop score $<5$, that is $16.1 \%$ and its $9.1 \%$ when the Bishop score $\geq 5$. Maceret al and Francis et al also found a statistically significant increase in the risk of cesarean section among nulliparous induced women if Bishop score $<5$ and hence present study is comparable with the same..$^{5,8}$

Birth weight is an independent risk factor for the rising cesarean section rates. In the present study birth weight $>3.5 \mathrm{~kg}$ is associated with statistically significant increase in cesarean section rate of $41.7 \%$. This is similar to the trials done by Prysak et al and Seyb et al, who found that there is a twofold increased risk of cesarean section rate with increase in birth weight. ${ }^{7,9}$

The induced and spontaneous group was analyzed after excluding the risk factors to determine whether induction per se in low risk population, increased the risk of cesarean section. The risk factors excluded were Bishop score $<5$, babies with birth weight $>3.5 \mathrm{~kg}$ and maternal age $>30$ years.

In the present study after the analysis it was concluded that cesarean section rate in the induced group was not statistically higher than the spontaneous group proving that induction per se is not associated with increased cesarean section rate. When it is associated with the abovementioned risk factors, the cesarean section risk was increased. This was similar to the study done by Prysak et al where they concluded that cesarean section was increased in the population who had significant risk factors such as nulliparity, poor Bishop score, gestational age $>287$ days, birth weight $>3800$ gms. ${ }^{7}$ However the conclusion from the study by Maslow and Sweeny et al, was contradictory that is induction remained a significant risk factor for cesarean delivery. ${ }^{6}$

In the present study the duration of first and second stage of labor in spontaneous group is more than the induced group, both in primipara and multipara except for second stage in multipara. This is comparable with the study done by Macer et al, where similar to this study the duration of labor in first and second stage in both groups are comparable and moreover the duration first stage of labor in multipara is more in spontaneous group when compared to their counterpart induced group. ${ }^{5}$ The conclusion from the present study is contradicting with the study done by Vahratianet A al, who concluded that there is statistically significant prolongation of duration of first and second stage of labor in both primipara and multipara in the induced group. ${ }^{10}$ In this study there is significant difference in the duration of second stage of labor in primipara, where induced is less with a $\mathrm{p}$ value of 0.038 .

In the present study the most common indication for cesarean section among the induced group is failed induction followed by fetal distress and then meconium stained liquor. On analyzing the failed induction cases it was observed that 5 cases had occipitoposterior position in the intra-op and 3 cases had loop of cord around the neck. Among the cases of fetal distress in the induced group, 3 cases had meconium stained liquor in the intraop, 2 cases had loop of cord around the neck and one case 
had true knot. Among the spontaneous group the most common indication is fetal distress.

In this present study the total number of meconium stained liquor in the induction group is and that in spontaneous group is 21 . In this study meconium stained liquor as an indication for cesarean section is found in 3 cases, which accounts for $4.8 \%$ in the induced group and among the spontaneous group meconium stained liquor is taken as an indication in 4 cases which accounts to $16.6 \%$. This result is comparable with the previous trials done by Cole et al, Smith et al and Kato K et al. ${ }^{11-13}$ This can be explained by the hypothesis that fetus in stress induces labor and hence meconium can be observed in cases of spontaneous group than the induced group. However, meconium and its associated complications are less in induced group than the spontaneous group.

In the present study the risk of instrumental delivery among the two groups, induced and spontaneous were comparable. Moreover, the risk of instrumental delivery was $4 \%$ in induced labor cases and $5.5 \%$ in spontaneous labor cases. These results are comparable with Prysak et al. ${ }^{7}$

In the present study the maternal intrapartum complications are $3.5 \%$ in induced group and $5 \%$ in spontaneous group. This is comparable to the study done by Macer et al, where they found no increase in intrapartum complications with induction of labor. ${ }^{5}$

The risk of neonatal complications was comparable between both the groups with $14 \%$ in induced group and $8.5 \%$ in spontaneous group. This is comparable with the studies done by Macer et al, Smith et al, Prysak et al. 5,7,12 In all these studies the neonatal complications among the induced and spontaneous group were comparable and hence indicating that elective induction per se does not pose any harm to fetus. The most common complication in the induced group is hyperbilirubinemia that is 17 cases. Out of these 17 cases on analysis it was noted that oxytocin was used for induction of labor in 10 cases.

\section{CONCLUSION}

From the present study we have concluded that elective induction of labor at term does not increase the risk for cesarean section in carefully selected low risk population. This study concluded that elective induction is associated with increased cesarean section rate, in the presence of the risk factors like nulliparity, Bishop score $<5$ and birth weight $>3.5 \mathrm{~kg}$. Moreover the hypothesis of this study that elective induction of labor in carefully selected low risk population does not pose any increased risk to the mother or fetus has been proved. However, elective induction of labor was not associated with prolongation of duration of labor, both first stage and second stage in primipara and multipara. In fact, the duration of second stage in primipara was significantly less than the spontaneous group. There is no significant difference in the maternal complications, neonatal complications and NICU admissions in both the groups. In this study maternal complication rate was less among the induced group than the spontaneous group. Neonates among the induced group mostly had hyperbilirubinemia and most of them out of this were induced with oxytocin. Since most of the women are employed now and hence elective induction done for the convenience of the physician and patient, the women undergoing elective induction should be informed about this before they undergo the same.

\section{ACKNOWLEDGMENTS}

Authors would like to acknowledge my teacher and guide Dr. Lakshmi Manjeera. M, Professor and HOD, Department of Obstetrics and Gynaecology, K. S. Hegde Medical Academy, Mangalore for her guidance and supervision during this study. Author also would like to thank the labour room nursing staff for their co-operation as well.

\section{Funding: No funding sources \\ Conflict of interest: None declared \\ Ethical approval: Not required}

\section{REFERENCES}

1. Eke AC, Okigbo C. Mechanical methods for induction of labor: RHL Commentary (Last revised: 1 Aug 2012). The WHO Reproductive Health Library; Geneva: World Health Organization.

2. Cunningham, Leveno, Bloom, Spong, Dash, Hoffman, Casey, Sheffield (editors). Induction and augmentation of labor. Williams Obstetrics. $24^{\text {th }}$ ed. Mc Graw-Hill;2014:523-534.

3. Zhang J, Yancey MK, Henderson CE. U.S. National trends in labor induction;1989-1998. J Reprod Med. 2002;47(2):120-4.

4. Konar H (editor). Induction of labor. DC Dutta's Textbook of Obstetrics. $8^{\text {th }}$ ed. 2013:598-608.

5. Macer JA, Macer CL. Elective induction versus spontaneous labor: A retrospective study of complications and outcome. Am J Obstet Gynecol. 1992;166:1690-7.

6. Maslow AS, Sweeney AL. Elective induction of labor as a risk factor for cesarean delivery among low risk woman at term. Obstet Gynecol. 2000;95:917-922.

7. Prysak M, Castronova FC. Elective induction versus spontaneous labor a case control analysis of safety and efficacy. Obstet Gynecol. 1998;92:47-52

8. Sande HA, Tuveng J, Fonstelier T. A prospective randomized study of induction of labor. Int $\mathrm{J}$ Gynaecol Obstet. 1983;21: 333-6.

9. Seyb ST, Berka RJ, Socol ML, Dooley SL. Risk of Cesarean Delivery with Elective Induction of labor at term in nulliparous women. Obstet Gynecol. 1999;94:600-7. 
10. Vahratian A, Zhang J, Troendle JF. Labor progression and risk of cesarean delivery in electively induced nulipara. Obstet Gynecol 2005;105:698-704.

11. Cole RA, Howie PN, Macnaughton MC. Elective induction of labor: A randomized prospective trial. Lancet. 1975;1:767-70.

12. Smith LP, Nagourney BA. Hazards and benefits of elective induction of labor. Am J Obstet Gynecol. 1984;148:579-585.
13. Kato K, Nagata I, Furuya K, Makimura N. Programmed induction of labor for primiparous women to ensure day time delivery. Asia Oceania J Obstet Gynecol. 1987;13:405-15.

Cite this article as: Babu S, Manjeera ML. Elective induction versus spontaneous labor at term: prospective study of outcome and complications. Int J Reprod Contracept Obstet Gynecol 2017;6:4899907. 